Check for updates

Cite this: Mater. Adv., 2020 1,2323

Received 9th July 2020,

Accepted 17th August 2020

DOI: 10.1039/d0ma00493f

rsc.li/materials-advances

\title{
3D carbon-coated stannous sulfide-molybdenum disulfide anodes for advanced lithium-ion batteries $\dagger$
}

\author{
Yuanyi Luo, $\ddagger$ Chunxia Chen, $\$$ Weicheng Sun, Ludi Shi, (D) Yemao Lin, \\ Guangtao Cong, * Jiali Yu, Caizhen Zhu (D)* and Jian Xu (D)
}

\begin{abstract}
Metal sulfides have been extensively studied as alternative anodes for lithium-ion batteries (LIBs) due to their high specific capacity, which comes from their combined conversion and alloying/de-alloying reactions with lithium, forming $\mathrm{Li}_{2} \mathrm{~S}$ and corresponding lithium alloys, respectively. However, the large volume fluctuation during cycling, low electronic/ionic conductivities of both metal sulfides and $\mathrm{Li}_{2} \mathrm{~S}$, and the electrochemical inactivity of $\mathrm{Li}_{2} \mathrm{~S}$ lead to poor reversibility and stability. Here, we report a facile way to synthesize a three-dimensional carbon-coated stannous sulfide-molybdenum disulfide composite (3D SnS-MoS 2 aC) which is proposed to alleviate the aforementioned problems. 3D SnS-MoS 2 aC exhibits a highly porous structure, which enhances the contact between the electrode and the electrolyte, promotes the transport of both electrons and $\mathrm{Li}^{+}$, and buffers the volume change during cycling. $\mathrm{MoS}_{2}$ contributes to

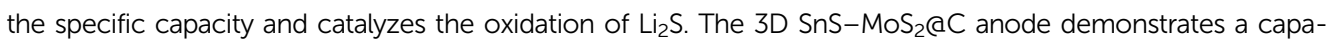
city of $887.1 \mathrm{~mA} \mathrm{~h} \mathrm{~g}^{-1}$ for the first cycle at $200 \mathrm{~mA} \mathrm{~g}^{-1}$ and achieves a capacity retention of $97.1 \%$ over 200 cycles. In addition, the ternary composite exhibits a superior rate performance and cycling lifespan, achieving a gravimetric capacity of $651.2 \mathrm{~mA} \mathrm{~h} \mathrm{~g}^{-1}$ at $1000 \mathrm{~mA} \mathrm{~g}^{-1}$ after 500 cycles. The proposed facile and effective strategy could be universally applied to other metal sulfide-based electrodes.
\end{abstract}

\section{Introduction}

LIBs have dominated the area of electrochemical energy storage for the past two decades, owing to their high energy/power density, long lifespan, and low-maintenance. ${ }^{1-3}$ Although many battery systems have been indicated to be capable of delivering extremely high theoretical energy density (e.g., lithium-oxygen and lithium-sulfur), they suffer from severe parasitic reactions, leading to poor rate capability, low energy efficiency, and a short cycle life. Therefore, intensive research efforts are still devoted to the optimization of LIBs. As one of the most successful anode materials, graphitized carbon has been widely used in commercialized LIBs for its safety and reversibility; however, its application is reaching a bottleneck imposed by low specific capacity. Moreover, metallic lithium dendrites are easily formed and deposited on the graphite surface upon overcharging, which can lead to short-circuits.

Alternative anodes with improved specific capacity and safety have been intensively explored. ${ }^{4-14}$ Owing to their superior redox

Institute of Low-Dimensional Materials Genome Initiative, College of Chemistry and Environmental Engineering, Shenzhen University, Shenzhen, Guangdong, 518060,

P. R. China.E-mail: gtcong@szu.edu.cn, czzhu@szu.edu.cn

$\dagger$ Electronic supplementary information (ESI) available. See DOI: 10.1039/d0ma00493f

$\dagger$ These authors contributed equally to this work. reversibility and high specific capacity, metal sulfides (e.g., FeS, $\mathrm{CoS}$, NiS, and ZnS) have been widely exploited as potential anodes for LIBs. ${ }^{15-24}$ Among them, SnS exhibits one of the highest theoretical $\mathrm{Li}^{+}$storage capacity $\left(1137 \mathrm{~mA} \mathrm{~h} \mathrm{~g}^{-1}\right)$. However, there remain four key challenges to be addressed in the application of SnS anodes: (1) SnS undergoes huge volume fluctuations during cycling, leading to exfoliation and repeated formation and destruction of the solid electrolyte interphase film (SEI); (2) the inherent low electronic conductivity of SnS inevitably deteriorates the rate performance of the electrode; (3) SnS particles tend to agglomerate due to the high surface energy and the formation of large SnS particles elongates the transportation path for both electrons and $\mathrm{Li}^{+}$, which inevitably mitigates the rate performance; ${ }^{25-27}$ and (4) as one of the lithiation products of $\mathrm{SnS}, \mathrm{Li}_{2} \mathrm{~S}$ exhibits slow oxidation kinetics during de-lithiation. ${ }^{28-30}$ Many strategies have been proposed to address these challenges, including tuning the morphology and the structure, ${ }^{27}$ expanding the interlayer distance, ${ }^{31}$ and impregnating SnS into a conductive carbonaceous matrix. ${ }^{32}$ However, the poor conductivity of the SnS layer coated on the carbon support greatly mitigates its high rate performance. ${ }^{33,34}$ In addition, the bulk SnS nanosheets grown on the carbon backbone are still very thick, which acts as the main barrier to the fast transfer of both electrons and $\mathrm{Li}^{+}$. 
To overcome the aforementioned issues of SnS anodes, we propose a facile method of intergrowth of a 3D SnS- $\mathrm{MoS}_{2} @ \mathrm{C}$ nanostructure. The designed porous composite material demonstrates excellent electrochemical performance, benefitting from the following three advantages: (1) the unique 3D interconnected porous structure exhibits an enhanced specific surface area which will promote the transport of both electrons and $\mathrm{Li}^{+}$. The porous structure of SnS provides ample space to accommodate the volume fluctuation during cycling; (2) both SnS and $\mathrm{MoS}_{2}$ are covered by a porous carbon layer, which will mitigate the agglomeration of both the $\mathrm{SnS}$ and $\mathrm{MoS}_{2}$ particles; (3) the addition of $\mathrm{MoS}_{2}$ contributes to the specific capacity and the existence of the Mo intermediate not only significantly improves the oxidation kinetics of $\mathrm{Li}_{2} \mathrm{~S}$ by reducing the activation potential of $\mathrm{Li}_{2} \mathrm{~S},{ }^{35-37}$ but also acts as a host to the polysulfide intermediates, which inhibits the notorious polysulfide shuttling and improves the cycling stability. ${ }^{28-30,38-42}$ The proposed 3D SnS- $\mathrm{MoS}_{2} @ \mathrm{C}$ porous composite demonstrates improved reversibility, capability, and cycle life over its bulky SnS@C and 3D SnS@C counterparts, representing a facile and effective solution to boost the performance of the SnS anodes and it could potentially be applied to the design of other metal sulfide-based electrodes.

\section{Materials and methods}

\section{Preparation of SnS-based composites}

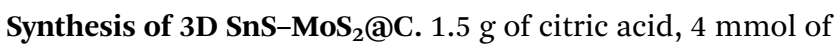
$\mathrm{SnCl}_{2} \cdot 2 \mathrm{H}_{2} \mathrm{O}$ and $10 \mathrm{~g} \mathrm{NaCl}, 8 \mathrm{mmol}$ thiourea, and $2 \mathrm{mmol}$ ammonium tetrathiomolybdate were sequentially added to $50 \mathrm{~mL}$ of $\mathrm{H}_{2} \mathrm{O}$, followed by constant stirring until the mixture turns into a clear solution. The solution was freeze-dried for $48 \mathrm{~h}$. The obtained product was first sintered at $350{ }^{\circ} \mathrm{C}$ for 3 hours and then at $700{ }^{\circ} \mathrm{C}$ for another 3 hours under an inert nitrogen atmosphere. A 2-step annealing process was adopted to ensure first sulfurization of $\mathrm{SnCl}_{2} \cdot 2 \mathrm{H}_{2} \mathrm{O}$ into $\mathrm{SnS}$ under mild conditions at $350{ }^{\circ} \mathrm{C}$ and then complete decomposition of ammonium tetrathiomolybdate and carbonization of citric acid at $700{ }^{\circ} \mathrm{C}^{26,43}$ After that, the product was filtered and rinsed with deionized water. Finally, the sample was dried and stored in a glove box for further characterization. The synthesis of 3D SnS@C follows the same procedure as that of 3D SnS$\mathrm{MoS}_{2}$ @C except that $2 \mathrm{mmol}$ ammonium tetrathiomolybdate was not used during the first step. For the synthesis of SnS@C, only citric acid, $\mathrm{SnCl}_{2} \cdot \mathrm{H}_{2} \mathrm{O}$, and $8 \mathrm{mmol}$ thiourea were added to deionized water during the solution preparation process, followed by the same freeze-drying, high-temperature treatment, and cleaning and drying procedure.

\section{Material characterization}

Surface area and pore size distribution were investigated using a BELSORP-max instrument at $77 \mathrm{~K}$ based on the BrunauerEmmett-Teller (BET) models. Inductively coupled plasma-atomic emission spectroscopy (ICP-AES) was performed on an OPTIMA2100DV spectrometer. Field emission scanning electron microscopy (FESEM) was performed on a JSM7800F spectrometer and transmission electron microscopy (TEM) was conducted on a JEM2100 spectrometer. Elemental distribution and composition were analyzed with energy-dispersive X-ray spectroscopy (EDS). $\mathrm{X}$-ray powder diffraction (XRD) measurements were conducted using MiniFlex600 $(\mathrm{Cu}-\mathrm{K} \alpha)$ at $40 \mathrm{kV}$ and $15 \mathrm{~mA}$. Raman spectroscopy (Raman) was performed at a light wavelength of $532 \mathrm{~nm}$ and a test range of $100-8000 \mathrm{~cm}^{-1}$. X-ray photoelectron spectroscopy (XPS) data were collected on a K-Alpha+ electronic spectrometer (Thermo Scientific).

\section{Electrochemical measurement}

Lithium metal half-cells were assembled using the standard 2032 lithium-ion button cells in an argon-filled glove box. The synthesized composites (70 wt\%) were mixed with acetylene black (AB, $20 \mathrm{wt} \%$ ) and sodium alginate (SA, $10 \mathrm{wt} \%$ ), forming a uniform slurry, which was evenly coated onto $\mathrm{Cu}$ foil. To study the influence of the active material content on the performance of the 3D SnS-MoS $@$ @C electrodes, electrodes with higher active material content (90 wt\% 3D SnS- $\mathrm{MoS}_{2}$ @C, $5 \mathrm{wt} \% \mathrm{AB}$, and $5 \mathrm{wt} \% \mathrm{SA}$ ) were prepared and tested. The prepared electrodes were then dried and cut out for further use. The loading of the active material on each electrode was controlled to be $\sim 1.5 \mathrm{mg} \mathrm{cm}^{-2}$. Lithium foil, 1.0 $\mathrm{M} \mathrm{LiPF}_{6}$ in DMC/EC (v/v = 1/1), and polypropylene (PP) were used as the anode, the electrolyte, and the separator, respectively. Charge/discharge cycling tests were conducted on a LAND CT2001A battery tester from 0.01 to 3.0 V. Cyclic voltammetry (CV) was conducted on a CHI660E workstation within the same voltage range.

\section{Results and discussion}

\section{Structure and morphology of 3D SnS-MoS $\mathrm{MCC}_{2}$}

The synthesis of the porous 3D SnS-MoS $@$ @C composite involved a facile and mild strategy (Fig. 1). Sodium chloride $(\mathrm{NaCl})$ was employed as the template to generate the porous structure, and stannous chloride dihydrate $\left(\mathrm{SnCl}_{2} \cdot 2 \mathrm{H}_{2} \mathrm{O}\right)$, ammonium tetrathiomolybdate $\left(\left(\mathrm{NH}_{4}\right)_{2} \mathrm{MoS}_{4}\right)$, thiourea, and citric acid were used as the sources of tin, molybdenum, sulfur, and carbon, respectively. A solution mixture of the precursors was first freeze-dried and then treated at a high temperature. 3D SnS- $\mathrm{MoS}_{2} @ \mathrm{C}$ was generated after removing the $\mathrm{NaCl}$ template of the carbonation product with deionized water.

First, we examined the morphology of 3D SnS-MoS $\mathrm{MC}_{2}$ and SnS@C with FESEM (Fig. 2a, b and d). 3D SnS-MoS $@$ @C has a large number of porous structures, while SnS@C has no obvious pore structure. The overall morphology of the 3D SnS- $\mathrm{MoS}_{2} @ \mathrm{C}$ composite resembles that of white fungus (Fig. 2c). There are a large number of continuous three-dimensional carbon networks with a pore size distribution between $100 \mathrm{~nm}$ and $1 \mu \mathrm{m}$. The morphology of 3D SnS shares the same structure with 3D SnS- $\mathrm{MoS}_{2}$ @C (Fig. S1, ESI $\dagger$ ), which suggests the universality of the proposed strategy to prepare a highly porous structure. The specific surface areas of 3D SnS- $\mathrm{MoS}_{2} @ \mathrm{C}$, 3D SnS@C and SnS@C were found to be 196.4, 155.5, and $11.0 \mathrm{~m}^{2} \mathrm{~g}^{-1}$, 


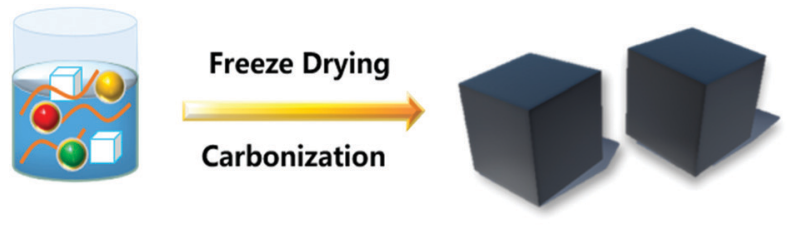

$\mathrm{SnCl}_{2} \cdot 2 \mathrm{H}_{2} \mathrm{O}$
Thiourea

Fig. 1 Synthetic procedure for 3D SnS-MoS $a$ C.

respectively (Fig. S2, ESI $\dagger$ ), which agrees well with the FESEM results. The enlarged surface area of the 3D SnS- $\mathrm{MoS}_{2} @ \mathrm{C}$ and 3D SnS@C would enhance the contact between the electrode/ electrolyte, leading to a reduced transportation path for both electrons and $\mathrm{Li}^{+}$. EDS was conducted to further study the elemental composition of 3D SnS-MoS $@$ C, which reveals the existence and even the distribution of $\mathrm{C}$ (red), $\mathrm{N}$ (green), Mo (purple), S (orange), and Sn (blue) over the composite (Fig. 2e-j). The contents of $\mathrm{MoS}_{2}$ and $\mathrm{SnS}$ in 3D SnS-MoS @C were determined to be around $18.8 \mathrm{wt} \%$ and $36.5 \mathrm{wt} \%$, respectively, on the basis of the ICP-AES analysis, which gives a SnS to $\mathrm{MoS}_{2}$ mole ratio of $2.1: 1$, in agreement with the mole ratio of their corresponding precursors and also agrees well with the EDS results (Fig. S3, ESI $\dagger$ ).
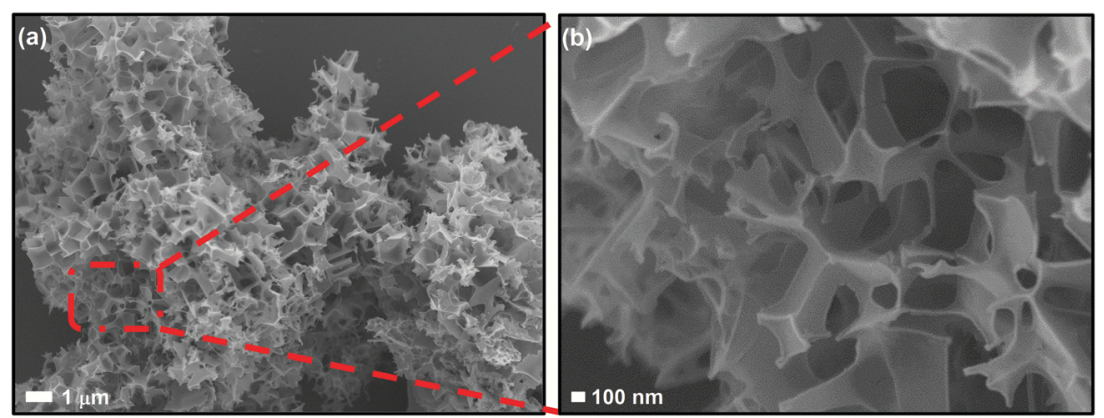
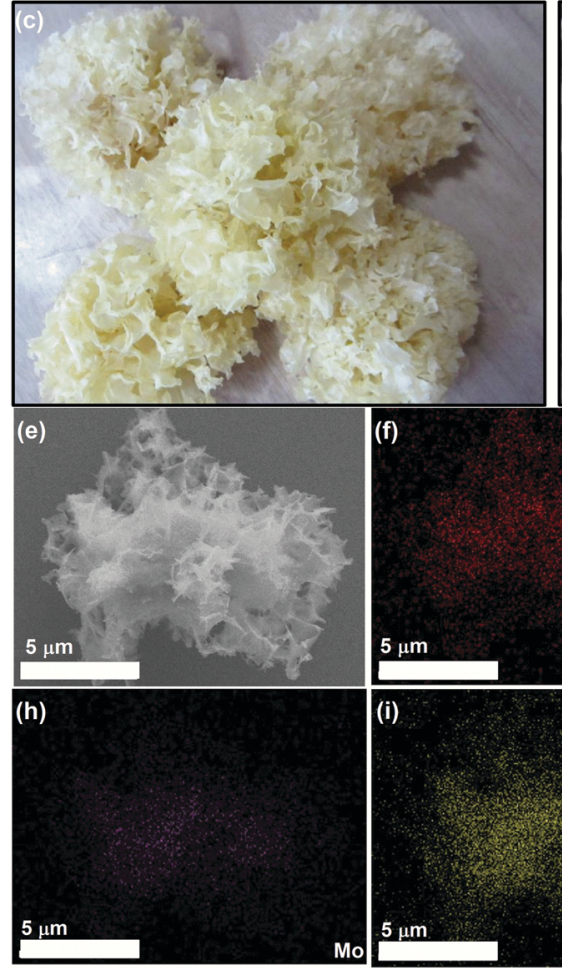

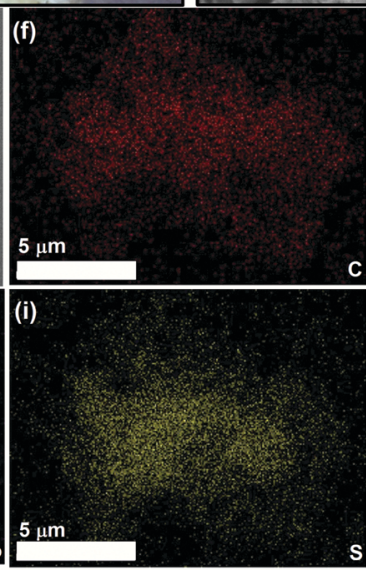

Wash

Distilled Water

$\mathrm{NaCl}$

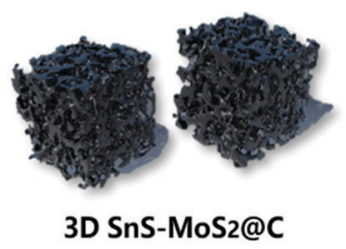

Citric Acid
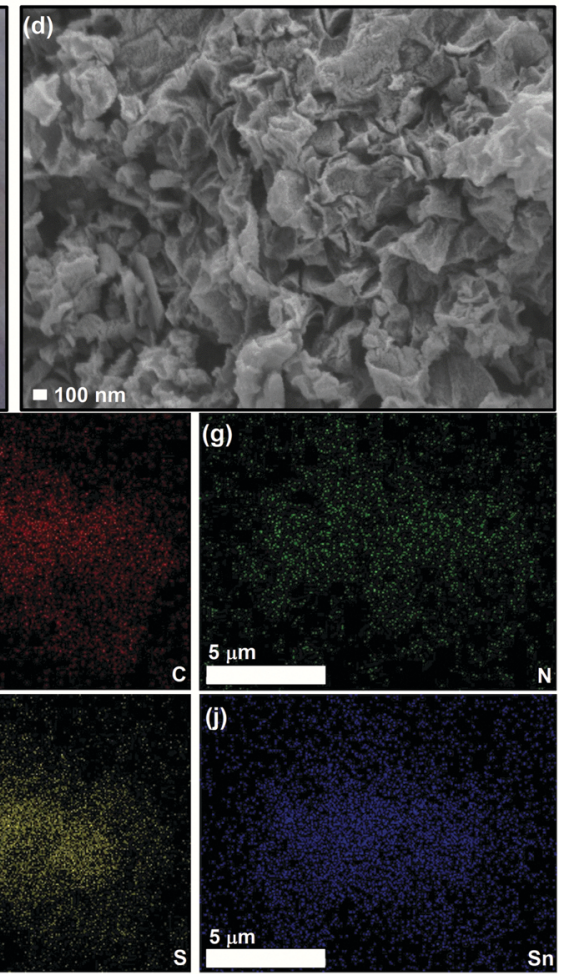

Fig. 2 (a) and (b) FESEM images of the as-prepared 3D SnS-MoS $(a C$. (c) Digital image of white fungus. (d) FESEM images of SnS@C and (e)-(j) EDS mapping (C, N, Mo, S, and Sn) images of the 3D SnS-MoS2. 
(a)

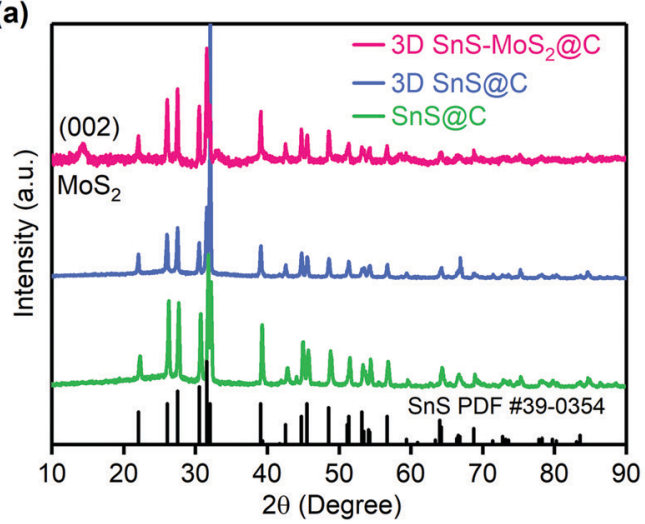

(b)

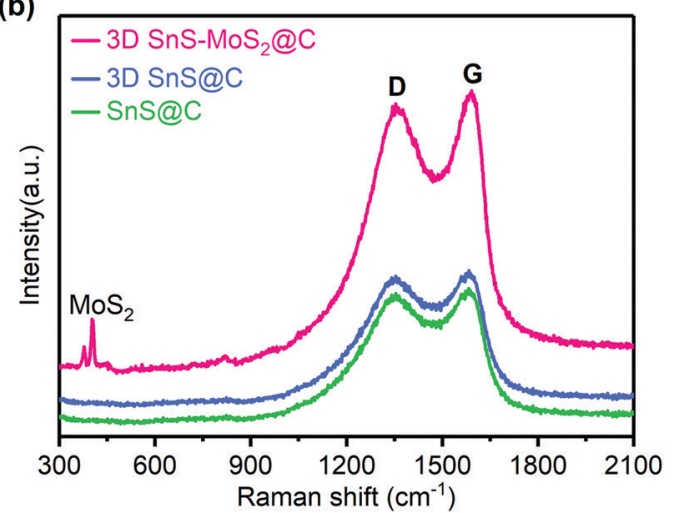

Fig. 3 XRD (a) and Raman (b) spectra of SnS@C, 3D SnS@C, and 3D SnS-MoS 2 aC. The powder diffraction file (PDF) standards for SnS is included for reference.

The crystal structures of the 3D SnS- $\mathrm{MoS}_{2} @ \mathrm{C}, 3 \mathrm{D}$ SnS@C, and SnS@C were studied using XRD (Fig. 3a). All the three samples demonstrated the high crystallinity of SnS and the diffraction peaks at $22.01^{\circ}, 26.01^{\circ}, 27.47^{\circ}, 31.53^{\circ}, 31.97^{\circ}$, $39.05^{\circ}, 45.50^{\circ}, 48.51^{\circ}$, and $53.15^{\circ}$ were associated with the (110), (120), (021), (111), (040), (131), (002), (211) and (122) crystal faces of SnS (PDF \#39-0354), respectively. ${ }^{27,44}$ Compared to the XRD spectra of SnS@C and 3D SnS@C, an additional diffraction peak at around $14.2^{\circ}$ was observed for $3 \mathrm{D} \mathrm{SnS}-\mathrm{MoS}_{2} @ \mathrm{C}$, which could be assigned to the (002) facet of $\mathrm{MoS}_{2} \cdot{ }^{34,45}$ The Raman spectra of the three SnS-based composites reveal welldefined $\mathrm{D}$ and $\mathrm{G}$ bands which locate at 1357 and $1586 \mathrm{~cm}^{-1}$, respectively (Fig. $3 \mathrm{~b}$ ). The $\mathrm{D}$ band is assigned to the vibration of the defective carbon atoms, while the $\mathrm{G}$ band could be ascribed to the vibration of the $\mathrm{sp}^{2}$-hybridized carbon atoms. ${ }^{46}$ The intensity ratio $\left(I_{\mathrm{D}} / I_{\mathrm{G}}\right)$ could be calculated to estimate the defects and the disorder degree of the carbon material. The $I_{\mathrm{D}} / I_{\mathrm{G}}$ values of the SnS@C, 3D SnS@C, and 3D SnS- $\mathrm{MoS}_{2} @ \mathrm{C}$ were found to be $0.98,0.98$, and 0.96 , respectively, which indicates the abundancy of carbon defects in all the three samples. In addition, the additional peaks of 3D SnS-MoS $@$ @ near 406 and $382 \mathrm{~cm}^{-1}$ are associated with the $\mathrm{A}_{1 \mathrm{~g}}$ and $\mathrm{E}_{2 \mathrm{~g}}{ }^{1}$ vibrations of $\mathrm{MoS}_{2}$, respectively ${ }^{46}$ which agrees well with the XRD results.

TEM was employed to further examine the structure of the as-prepared 3D SnS- $\mathrm{MoS}_{2} @ \mathrm{C}$. The ternary composite shows a continuous porous structure with $\mathrm{SnS}$ and $\mathrm{MoS}_{2}$ particles embedded in the carbon skeleton (Fig. 4a), which could effectively mitigate the agglomeration of both the SnS and $\mathrm{MoS}_{2}$ particles. In addition, the as-prepared 3D SnS- $\mathrm{MoS}_{2} @ \mathrm{C}$ composite exhibits well-defined diffraction fringes with lattice pitches of $0.28,0.24$, and $0.68 \mathrm{~nm}$, which are associated with the (111) facet of SnS and the (103) and (002) facets of $\mathrm{MoS}_{2}$, respectively (Fig. 4b). ${ }^{47}$

The XPS survey spectrum of 3D SnS- $\mathrm{MoS}_{2}$ @C suggests that the as-prepared composite contains primarily Sn, Mo, N, C, S, and $\mathrm{O}$ elements (Fig. 5a), As shown in Fig. $5 \mathrm{~b}$, Sn $3 \mathrm{~d}_{3 / 2}$ and a strong peak of $\mathrm{Sn} 3 \mathrm{~d}_{5 / 2}$ with binding energies of 487.2 and $495.8 \mathrm{eV}$ appear, which could be assigned to $\mathrm{SnS}^{27}$ The characteristic peaks of $\mathrm{Mo}^{4+}$ in $\mathrm{MoS}_{2}$ could also be observed at 229.5 and $232.8 \mathrm{eV}$ (Fig. 5c). In addition, there is a weak peak of $\mathrm{Mo}^{6+} 3 \mathrm{~d}_{5 / 2}$ at $236.0 \mathrm{eV}$, indicating that trace $\mathrm{MoO}_{3}$ may exist in the material. ${ }^{48}$ The $\mathrm{N} 1 \mathrm{~s}$ spectrum in Fig. $5 \mathrm{~d}$ suggests that the $\mathrm{N}$ atom mainly exists in the form of pyridine and pyrrole type $\mathrm{N}$ in the composite. ${ }^{27}$ There are two main reasons for the presence of $\mathrm{N}$ in the material: (1) during high-temperature treatments, thiourea may react with $\mathrm{SnCl}_{2} \cdot \mathrm{H}_{2} \mathrm{O}$ to form ammonia and (2) the protective gas used for high-temperature carbonization is nitrogen. Therefore, under high-temperature conditions, both ammonia and nitrogen could promote the nitrogen-doping level of the composite. The doping level of nitrogen was estimated based on the EDS analysis. A nitrogen weight ratio of $3.96 \mathrm{wt} \%$ was determined for the 3D SnS-MoS $\mathrm{MCC}_{2}$
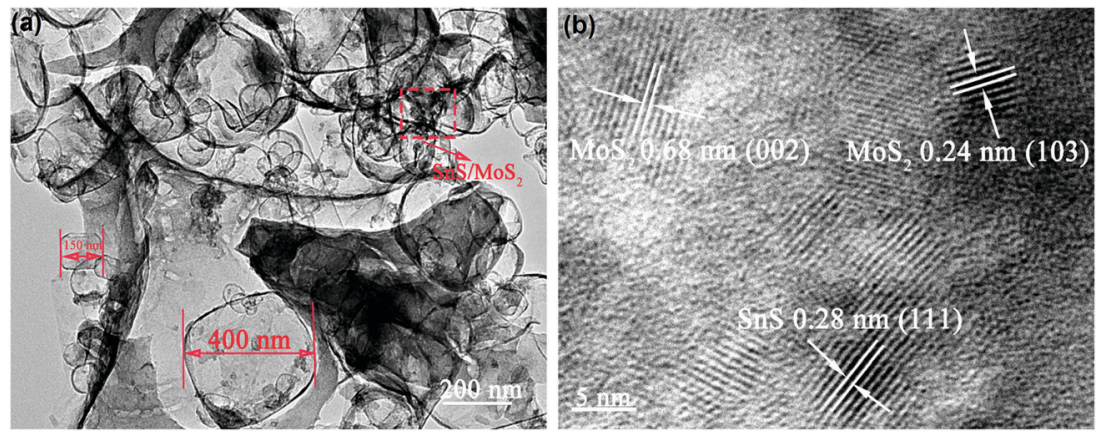

Fig. 4 TEM image (a) and high-resolution TEM (b) images of 3D SnS-MoS 2 aC. 
(a)

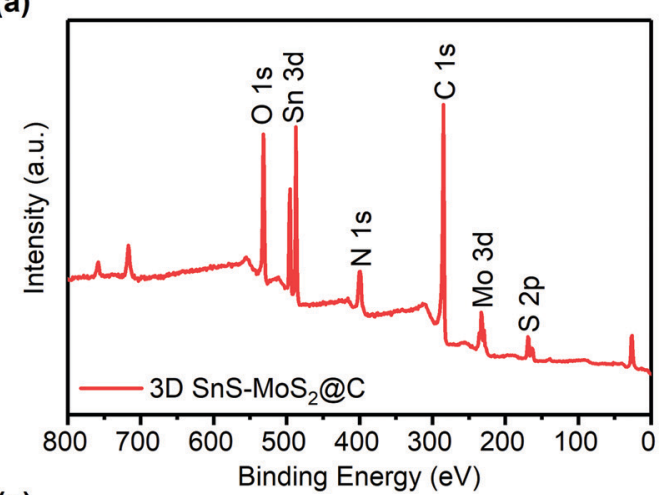

(c)

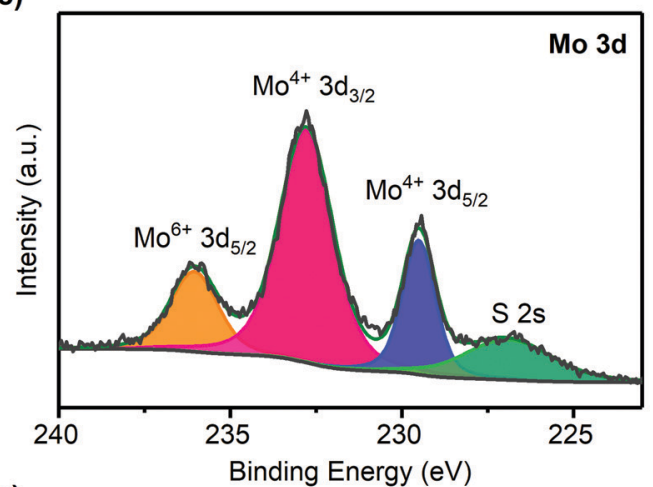

(e)

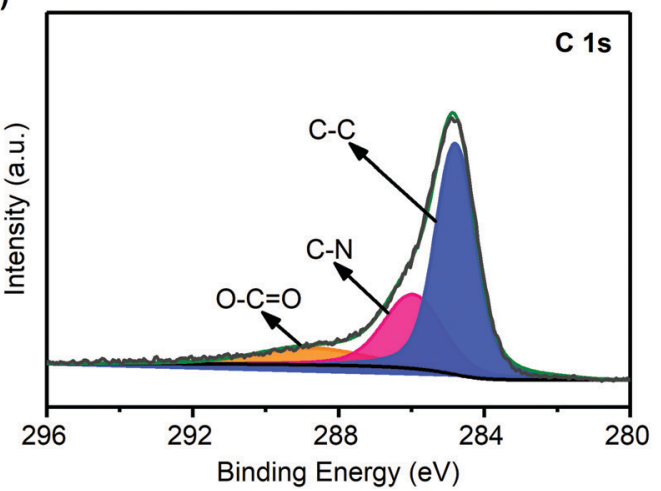

(b)

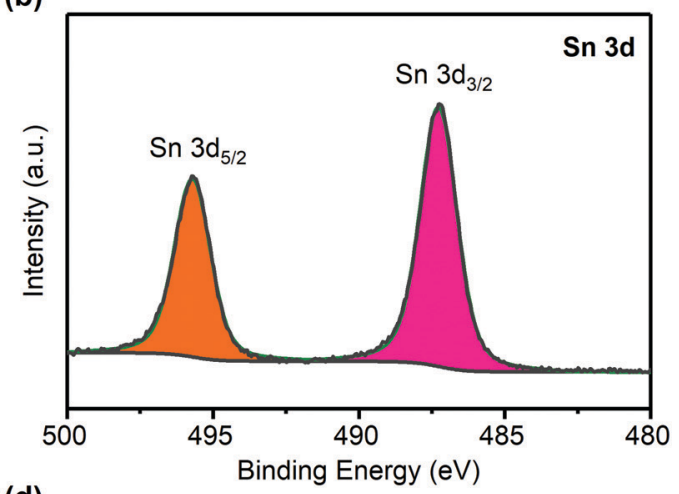

(d)

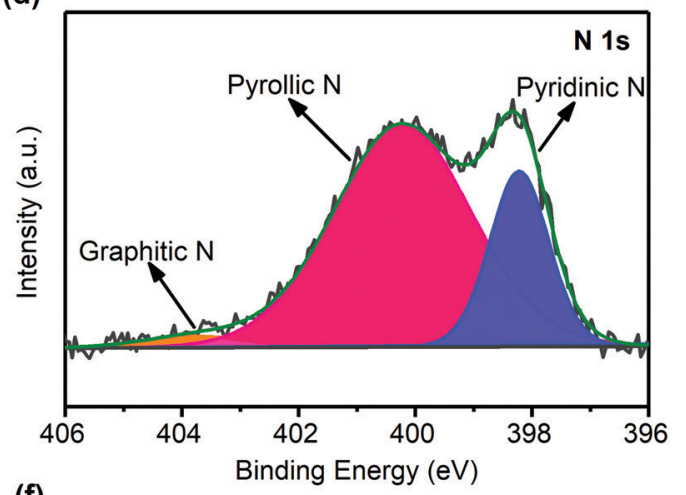

(f)

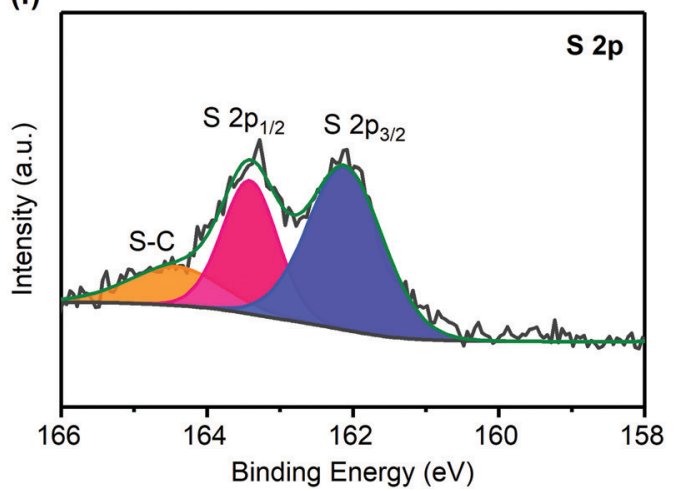

Fig. 5 (a) XPS survey spectrum of 3D SnS-MoS $a$ C. XPS spectra of Sn 3d (b), Mo 3d (c), N 1s (d), C 1s (e), and S 2p (f).

composite (Fig. S3, ESI $\dagger$ ). Extensive theoretical and experimental studies have showed that nitrogen doping of the carbon materials would enhance their electronic conductivity by tuning the Fermi level and increasing the fraction of the localized electronic states. ${ }^{4-51}$ In addition, the doped $\mathrm{N}$ atoms, especially pyridinic-N, exhibit a strong affinity to sulfide species, which would reduce the shuttling of the polysulfide intermediates. $^{52,53}$

Fig. 5e shows the XPS spectrum of $\mathrm{C} 1 \mathrm{~s}$. The peaks around $284.8,286.0$, and $288.6 \mathrm{eV}$ could be assigned to $\mathrm{C}-\mathrm{C}, \mathrm{C}-\mathrm{N}$, and $\mathrm{O}-\mathrm{C}=\mathrm{O}$, respectively. Recent studies suggest that heteroatom doping of carbon materials could effectively promote the electronic conductivity, leading to an improved rate performance. ${ }^{54,55}$ The high-resolution XPS spectrum of S 2 p reveals two peaks near 162.2 and $163.4 \mathrm{eV}$, which originate from $\mathrm{S}^{2-}$, and the peak near $164.5 \mathrm{eV}$ is associated with S-C (Fig. $5 f) .{ }^{56}$

\section{Electrochemical performance}

CV tests were first conducted to study the electrochemical behavior of 3D SnS-MoS ${ }_{2}$ @C (Fig. 6a). During the first cathodic scan, the broad peak at $0.81 \mathrm{~V}$ could be ascribed to the lithiation of $\mathrm{SnS}$ into $\mathrm{Li}_{2} \mathrm{~S}$ and $\mathrm{Sn}$, which is disguised by the simultaneous irreversible SEI formation. This broad peak disappeared during the subsequent scans, suggesting the formation of a stable SEI film during the first reduction. We notice that a new cathodic peak at $1.3 \mathrm{~V}$ evolved during the subsequent cycles, which could be assigned to the lithiation of SnS after the formation of the stable SEI. ${ }^{26,34}$ The broad peak at $0.31 \mathrm{~V}$ could be assigned to the reversible conversion process: $\mathrm{MoS}_{2}+4 \mathrm{Li}+4 \mathrm{e}^{-} \leftrightarrow \mathrm{Mo}+2 \mathrm{Li}_{2} \mathrm{~S}^{34}$ The broad peak near $0.1 \mathrm{~V}$ could result from the reversible alloying process between $\mathrm{Sn}$ and $\mathrm{Li}$, namely $\mathrm{Sn}+x \mathrm{e}^{-}+x \mathrm{Li}^{+} \leftrightarrow \mathrm{Li}_{x} \mathrm{Sn}(0 \leq x \leq 4.4) .{ }^{57}$ A series of oxidation peaks between 0.2 and $0.8 \mathrm{~V}$ could be observed, 
(a)

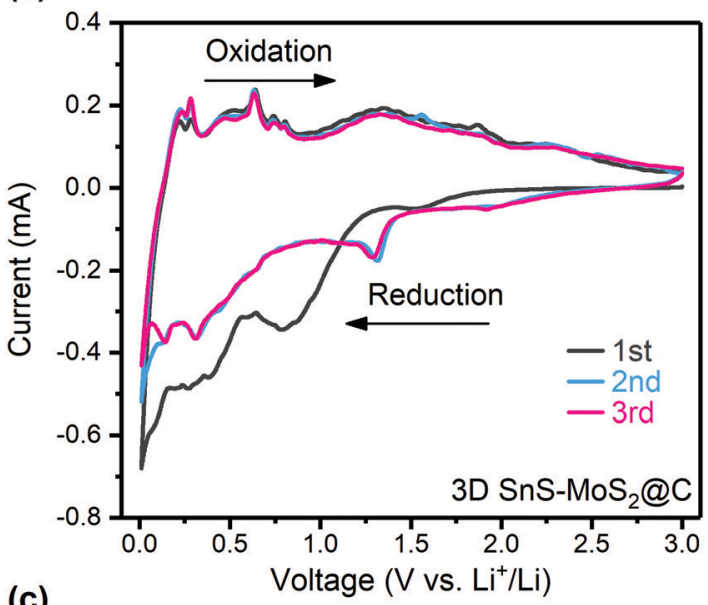

(c)

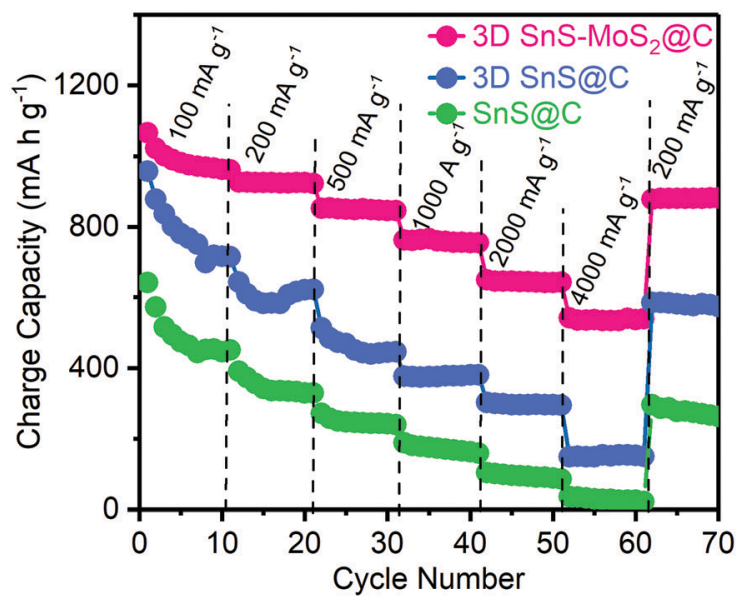

(b)
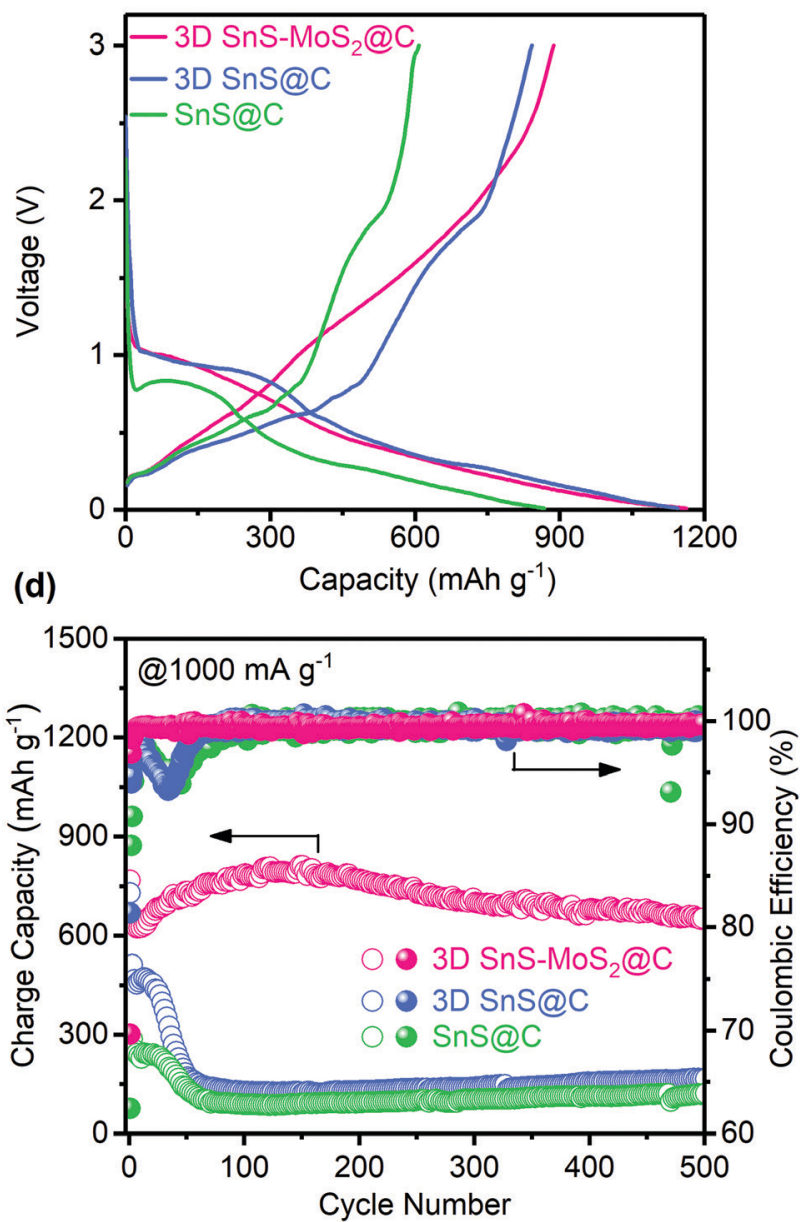

Fig. 6 Electrochemical characterization of the SnS-based electrodes. (a) Cyclic voltammetry (CV) of 3D SnS-MoS 2 (aC at $0.1 \mathrm{mV} \mathrm{s}^{-1}$. (b) Voltage versus capacity curves of the three SnS-based electrodes at $200 \mathrm{~mA} \mathrm{~g}^{-1}$. Rate capability (c) and long-term cycling performance (d) of the three SnS-based electrodes.

which is ascribed to the sequential de-alloying of $\mathrm{Li}_{x} \mathrm{Sn}$ and the conversion of $\mathrm{Mo}$ and $\mathrm{Li}_{2} \mathrm{~S}$ to $\mathrm{MoS}_{2}$ and $\mathrm{Li}^{+}{ }^{57}$ Two broad peaks around 1.8 and $1.34 \mathrm{~V}$ could be assigned to the conversion of SnS to Sn and $\mathrm{Li}_{2} \mathrm{~S} .{ }^{58,59}$ Significantly, the redox peaks of the subsequent $\mathrm{CV}$ curves almost coincide with each other, which suggests the superior stability and reversibility of 3D SnS- $\mathrm{MoS}_{2} @ \mathrm{C}$. Fig. 6b presents the first galvanostatic voltage profiles of the three SnS-based composites at $200 \mathrm{~mA} \mathrm{~g}^{-1}$. Two distinct plateaus could be observed during the discharge process. The first discharge plateau located between 0.8 and $1.0 \mathrm{~V}$ corresponds to the lithiation of SnS, forming Sn and amorphous $\mathrm{Li}_{2} \mathrm{~S}$, accompanied with the irreversible SEI formation. The second plateau between 0.2 and $0.5 \mathrm{~V}$ could be associated with the alloying reaction of Sn with Li. The 3D SnS- $\mathrm{MoS}_{2} @ \mathrm{C}$ anode demonstrates a superior stability and reversibility over the 3D SnS@C and SnS@C anodes upon repeated charge and discharge at low rates (Fig. S4 and S5, ESI $\dagger$ ). The first charge process delivered a gravimetric capacity of $887.1 \mathrm{~mA} \mathrm{~h} \mathrm{~g}^{-1}$ at $200 \mathrm{~mA} \mathrm{~g}^{-1}$. Remarkably, a high capacity of $861.8 \mathrm{~mA} \mathrm{~h} \mathrm{~g}^{-1}$ was maintained over 200 cycles with a high capacity retention of $97.1 \%$ and CEs close to $100 \%$. Although 3D SnS@C shares the same porous architecture with 3D SnS- $\mathrm{MoS}_{2} @ \mathrm{C}$, its cycling stability and capacity retention are much lower than those of 3D SnS- $\mathrm{MoS}_{2} @ \mathrm{C}$. The enhanced reversibility and stability of 3D SnS- $\mathrm{MoS}_{2} @ \mathrm{C}$ over 3D SnS@C originate from the reduced kinetic barrier of $\mathrm{Li}_{2} \mathrm{~S}$ oxidation as well as the mitigated polysulfide shuttling as discussed earlier. ${ }^{35-42}$ To evaluate the rate performance of the three SnS-based anodes, galvanostatic cycling tests with current densities in the range from 100 to $4000 \mathrm{~mA} \mathrm{~g}^{-1}$ were performed (Fig. 6c). The performance of the 3D SnS- $\mathrm{MoS}_{2} @ \mathrm{C}$ electrode is significantly improved over the SnS@C and 3D SnS@C counterparts. The achieved gravimetric capacities of all the three samples decreased with the increasing rates. When the applied current was increased to $4000 \mathrm{~mA} \mathrm{~g}^{-1}$, the gravimetric capacities of the SnS@C and 3D SnS@C electrodes were found to be 30 and $200 \mathrm{~mA} \mathrm{~h} \mathrm{~g}^{-1}$, respectively. Remarkably, the specific capacity of the 3D SnS- $\mathrm{MoS}_{2} @ \mathrm{C}$ composite stabilized around $533.7 \mathrm{~mA} \mathrm{~h} \mathrm{~g}^{-1}$ at $4000 \mathrm{~mA} \mathrm{~g}^{-1}$ and recovered to $880.8 \mathrm{~mA} \mathrm{~h} \mathrm{~g}^{-1}$ when the applied current was reduced to $200 \mathrm{~mA} \mathrm{~g}^{-1}$. The weight ratio of the active materials not only greatly influenced the performance of the electrodes but also directly determined their energy density. We notice 
that $70 \mathrm{wt} \%$ of 3D SnS- $\mathrm{MoS}_{2} @ \mathrm{C}$ is relatively lower compared to those of commercialized LIBs. Cycling of the 3D SnS-MoS ${ }_{2} @ \mathrm{C}$ electrode with $90 \mathrm{wt} \%$ active materials was performed (Fig. S6, ESI $\dagger$ ). Both electrodes shared similar high CEs close to $100 \%$ while the electrodes with $90 \mathrm{wt} \%$ active material suffered from more severe capacity fading than the ones with lower active material content. Further optimization of the electrode structural design is needed to improve the performance of the $3 \mathrm{D}$ SnS- $\mathrm{MoS}_{2} @ \mathrm{C}$ electrodes. The outstanding rate performance of the 3D SnS- $\mathrm{MoS}_{2} @ \mathrm{C}$ composites could be ascribed to the following two aspects: (1) the pore size lies between $100 \mathrm{~nm}$ and $1 \mu \mathrm{m}$ which greatly reduces the diffusion path of $\mathrm{Li}^{+}$and a large number of microspores enlarge the electrode/electrolyte contact area, which is beneficial for the rate performance of the anode ${ }^{26,60}$ and (2) the catalytic effect of Mo on the oxidation of $\mathrm{Li}_{2} \mathrm{~S}$ as well as its ability to regulate the conversion of polysulfide during de-lithiation. ${ }^{35-42}$ The rate capability of 3D SnS$\mathrm{MoS}_{2} @ \mathrm{C}$ was compared with that of the other two SnS-based composites at $1000 \mathrm{~mA} \mathrm{~g}^{-1}$ (Fig. 6d). During the first 50 cycles, the gravimetric capacities of both 3D SnS@C and SnS@C were sharply decreased to less than $200 \mathrm{~mA} \mathrm{~h} \mathrm{~g}^{-1}$, whereas 3D SnS$\mathrm{MoS}_{2} @ \mathrm{C}$ demonstrated stable cycling of more than 500 cycles with a gravimetric capacity of $651.2 \mathrm{~mA} \mathrm{~h} \mathrm{~g}^{-1}$ and an average $\mathrm{CE}$ of $99.75 \%$. The difference in the rate performance between 3D SnS- $\mathrm{MoS}_{2} @ \mathrm{C}$ and SnS@C was investigated by monitoring their morphology evolution during cycling. The 3D porous structure remained well-preserved while the structures of 3D SnS@C and SnS@C were shattered after 50 cycles (Fig. S7, ESI $\dagger$ ). Galvanostatic cycling tests of the full cell configuration with the $3 \mathrm{D}$ SnS- $\mathrm{MoS}_{2}$ @C anode and the commercial $\mathrm{LiFePO}_{4}$ cathode were conducted at $100 \mathrm{~mA} \mathrm{~g}^{-1}$ (Fig. S8, ESI $\dagger$ ). A gravimetric capacity of $485 \mathrm{~mA} \mathrm{~h} \mathrm{~g}^{-1}$ could be achieved with an average CE of $97.5 \%$ after 100 cycles. We notice that the initial CE is as low as $60 \%$, which could be associated with the irreversible SEI formation on the 3D SnS- $\mathrm{MoS}_{2}$ @C anode during the first charging process. The practical application of the full cell was also evaluated by powering programmed light-emitting diode (LED) fans. Three 3D SnS- $\mathrm{MoS}_{2} @ \mathrm{C} / \mathrm{LiFePO}_{4}$ full cells connected in series could power the LED fans for several minutes (Fig. S9 and Video, ESI $\dagger$ ).

Electrochemical impedance spectroscopy was conducted to probe the resistance evolution of the three SnS-based anodes before and after 50 cycles (Fig. S10, ESI $\dagger$ ). The total resistance of the 3D SnS@C and SnS@C electrodes gradually increases during cycling which might be related to their structure instability during repeated lilthiation and de-lithiation. In contrast, the total (a)

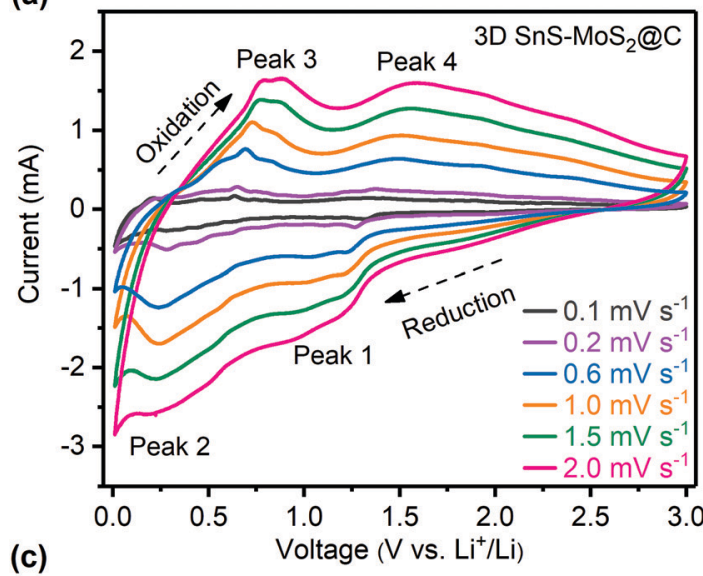

(c)

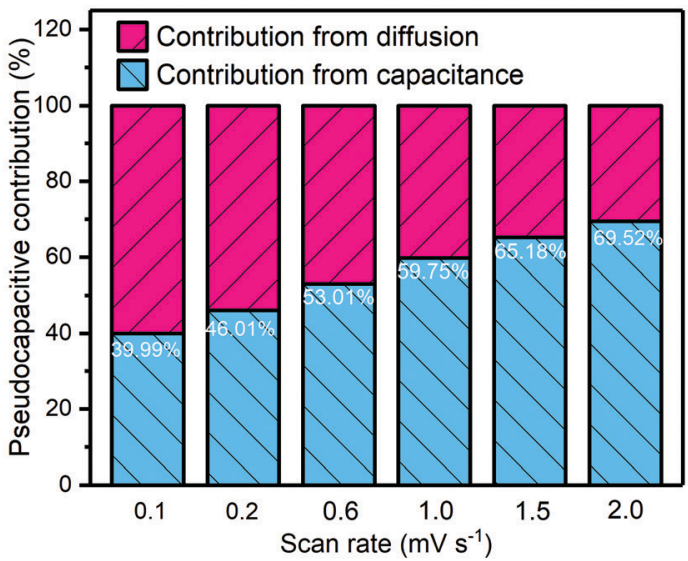

(b)

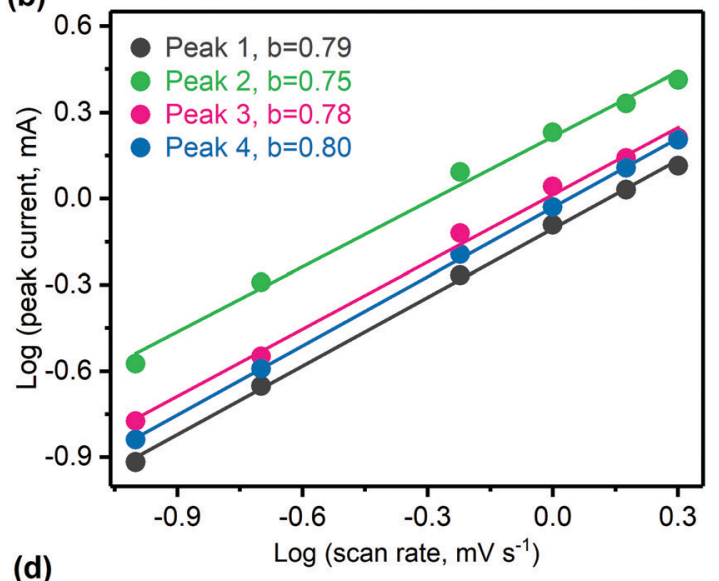

(d)

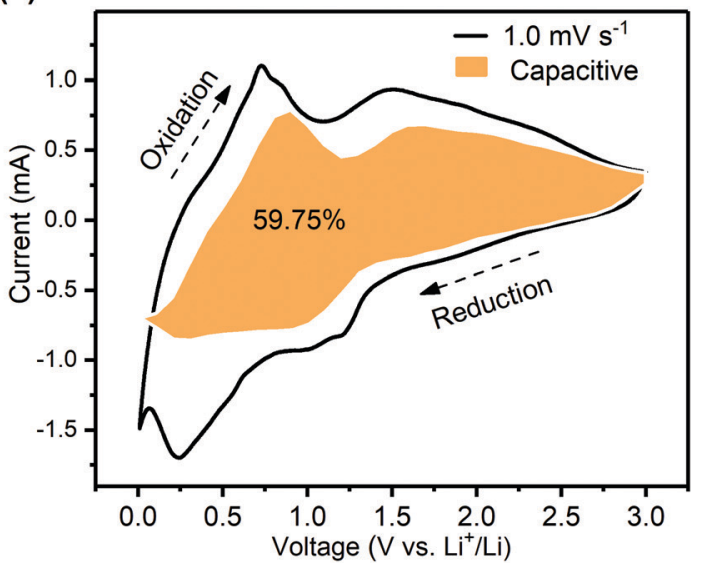

Fig. 7 (a) CV scans of the 3D SnS-MoS 2 CC anode at varying scan rates from 0.1 to $2.0 \mathrm{mV} \mathrm{s}^{-1}$. (b) Linear correlation between the logarithm of the peak currents and the logarithm of the scan rates. (c) Contribution of the pseudo-capacitive process at different scan rates depicted by bar charts. (d) Current contribution of the pseudo-capacitive process (orange area) during the CV tests at $1.0 \mathrm{mV} \mathrm{s}^{-1}$. 
resistance of the 3D SnS- $\mathrm{MoS}_{2}$ @C electrode decreased after cycling which could be ascribed to the improved wettability between the electrode and the electrolyte. The high-frequency semicircle could be ascribed to the charge transfer, and the lowfrequency slope could be assigned to the $\mathrm{Li}^{+}$diffusion behavior. As can be seen from the fitting results (Table S1, ESI $\dagger$ ), the total resistance consists of three components: charge transfer resistance $R_{\mathrm{ct}}$, film resistance $R_{\mathrm{f}}$, and the Warburg diffusion resistance $W$. Among all the three anodes, SnS@C exhibits the largest film resistance, which reflects the formation of a thick and unstable SEI film between the material and the electrolyte. The 3D SnS$\mathrm{MoS}_{2} @ \mathrm{C}$ composite has the smallest $R_{\mathrm{f}}$, suggesting the formation of a stable SEI over a unique three-dimensional porous structure. Both the Warburg impedance and charge transfer resistance of 3D SnS- $\mathrm{MoS}_{2} @ \mathrm{C}$ are smaller than those of the other samples, which agrees well with the rate performance results (Fig. 6c)

To differentiate the surface capacitance from the electrochemical reactions, $\mathrm{CV}$ tests of the 3D $\mathrm{SnS}-\mathrm{MoS}_{2}$ @C electrode with the scan rates varying from 0.1 to $2.0 \mathrm{mV} \mathrm{s}^{-1}$ were conducted (Fig. 7a). The current response at a specific voltage can be divided into two parts: (1) the current contribution of the surface capacitance and (2) the diffusion-controlled current contribution. The corresponding relationship is described as follows: ${ }^{61}$

$$
\begin{aligned}
& i(v)=k_{1} v+k_{2} v^{1 / 2}=a v^{b} \\
& \log i(v)=\log a+b \log v
\end{aligned}
$$

where $\nu$ is the scan rate, $i(v)$ is the measured current, $k_{1} \nu$ is the capacitive contribution, $k_{2} \nu^{1 / 2}$ is the diffusion-controlled current contribution, and $k_{1}, k_{2}, a$ and $b$ are constants. To simplify the relationship between $i(v)$ and $\nu$, the logarithmic form of eqn (1) is often adopted (eqn (2)). The constant $b$ has a value that lies in the range between 0.5 and 1.0. When $b$ approaches 0.5 , the reaction exhibits a slow semi-infinite diffusioncontrolled Faraday process, whereas if $b$ approaches 1.0, the reaction is dominated by a capacitive process. The calculated $b$ values correspond to two oxidation peaks and two reduction peaks which are $0.79,0.75,0.78$, and 0.80 , respectively, which implies that the redox reactions of the 3D SnS- $\mathrm{MoS}_{2} @ \mathrm{C}$ anode are determined by both capacitance and diffusion-controlled processes (Fig. 7b). Fig. 7c shows the capacitance fraction at different scan rates. The capacitive Li storage accounts for $59.7 \%$ at $1 \mathrm{mV} \mathrm{s}^{-1}$ (Fig. $7 \mathrm{~d}$ ), which is consistent with the results concluded from the $b$ values.

\section{Conclusions}

In summary, a rationally designed highly porous 3D SnS- $\mathrm{MoS}_{2} @ \mathrm{C}$ composite was successfully synthesized using a facile and mild procedure. The 3D SnS- $\mathrm{MoS}_{2} @ \mathrm{C}$ composite achieves a superior capacity of $861.8 \mathrm{~mA} \mathrm{~h} \mathrm{~g}^{-1}$ after 200 cycles at $200 \mathrm{~mA} \mathrm{~g}^{-1}$. In addition, the as-prepared ternary composite demonstrates an outstanding rate performance and a long lifespan as well. A remarkable capacity of $651.2 \mathrm{~mA} \mathrm{~h} \mathrm{~g}^{-1}$ was maintained after 500 cycles at $1000 \mathrm{~mA} \mathrm{~g}^{-1}$. This facile and effective method of preparing highly porous electrodes could potentially be applied to other metal sulfide-based electrodes.

\section{Conflicts of interest}

The authors declare no competing interest.

\section{Acknowledgements}

This work was supported by the National Natural Science Foundation of China (21805193 and 51673117), the Science and Technology Innovation Commission of Shenzhen (JCYJ20180305125319991, JCYJ20170818093832350, JCYJ20170818100112531， JSGG20170824112840518， JCYJ20180507184711069, JCYJ20170818101016362, and JCYJ20170817094628397), the Key R\&D Programme of Guangdong Province (2019B010941001 and 2019B010929002), and the China Postdoctoral Science Foundation (2017M622786, 2019M650212, and 2017M622787).

\section{References}

1 M. Armand and J. M. Tarascon, Nature, 2008, 451, 652-657. 2 M. Li, J. Lu, Z. Chen and K. Amine, Adv. Mater., 2018, 30, 1800561.

3 C. Kim, G. Song, L. Luo, J. Y. Cheong, S.-H. Cho, D. Kwon, S. Choi, J.-W. Jung, C.-M. Wang, I.-D. Kim and S. Park, ACS Nano, 2018, 12, 8169-8176.

4 M.-S. Balogun, M. Yu, Y. Huang, C. Li, P. Fang, Y. Liu, X. Lu and Y. Tong, Nano Energy, 2015, 11, 348-355.

5 W. Li, X. Li, J. Liao, B. Zhao, L. Zhang, L. Huang, G. Liu, Z. Guo and M. Liu, Energy Environ. Sci., 2019, 12, 2286-2297.

6 W. Li, J. Liao, X. Li, L. Zhang, B. Zhao, Y. Chen, Y. Zhou, Z. Guo and M. Liu, Adv. Funct. Mater., 2019, 29, 1903638.

7 W. Li, J. Yu, J. Wen, J. Liao, Z. Ye, B. Zhao, X. Li, H. Zhang, M. Liu and Z. Guo, J. Mater. Chem. A, 2019, 7, 16785-16792.

8 X. Xia, S. Deng, S. Feng, J. Wu and J. Tu, J. Mater. Chem. A, 2017, 5, 21134-21139.

9 H. Liang, J. Ni and L. Li, Nano Energy, 2017, 33, 213-220.

10 Y. Zhao, X. Li, B. Yan, D. Xiong, D. Li, S. Lawes and X. Sun, Adv. Energy Mater., 2016, 6, 1502175.

11 C. Wang, L. Wu, H. Wang, W. Zuo, Y. Li and J. Liu, Adv. Funct. Mater., 2015, 25, 3524-3533.

12 Y. Xu, S. Zheng, H. Tang, X. Guo, H. Xue and H. Pang, Energy Storage Mater., 2017, 9, 11-30.

13 J.-M. Liang, L.-J. Zhang, D.-G. XiLi and J. Kang, Rare Met., 2020, 1-14.

14 Y.-F. Huo, N. Qin, C.-Z. Liao, H.-F. Feng, Y.-Y. Gu and H. Cheng, J. Cent. South Univ., 2019, 26, 1416-1425.

15 T. Stephenson, Z. Li, B. Olsen and D. Mitlin, Energy Environ. Sci., 2014, 7, 209-231.

16 L. Zhao, X. Yu, J. Yu, Y. Zhou, S. N. Ehrlich, Y.-S. Hu, D. Su, H. Li, X.-Q. Yang and L. Chen, Adv. Funct. Mater., 2014, 24, 5557-5566. 
17 M.-R. Gao, Y.-F. Xu, J. Jiang and S.-H. Yu, Chem. Soc. Rev., 2013, 42, 2986-3017.

18 L. Zhang, H. B. Wu, Y. Yan, X. Wang and X. W. Lou, Energy Environ. Sci., 2014, 7, 3302-3306.

19 W. Qiu, J. Xia, H. Zhong, S. He, S. Lai and L. Chen, Electrochim. Acta, 2014, 137, 197-205.

20 J. Xiao, X. Wang, X.-Q. Yang, S. Xun, G. Liu, P. K. Koech, J. Liu and J. P. Lemmon, Adv. Funct. Mater., 2011, 21, 2840-2846.

21 J. Wang, H. He, Z. Wu, J. Liang, L. Han, H. L. Xin, X. Guo, Y. Zhu and D. Wang, J. Power Sources, 2018, 392, 193-199.

22 L. Ma, W. Zhang, L. Wang, Y. Hu, G. Zhu, Y. Wang, R. Chen, T. Chen, Z. Tie, J. Liu and Z. Jin, ACS Nano, 2018, 12, 4868-4876.

23 F. Jing, Q. Lv, J. Xiao, Q. Wang and S. Wang, J. Mater. Chem. A, 2018, 6, 14207-14214.

24 K. Yang, Q. Guo, H. Li, X. Hao, Y. Ma, M. Yang, T. Zhai, S. V. Savilov, V. V. Lunin and H. Xia, J. Power Sources, 2018, 402, 340-344.

25 P. He, Y. Fang, X.-Y. Yu and X. W. Lou, Angew. Chem., Int. Ed., 2017, 56, 12202-12205.

26 P. Xue, N. Wang, Y. Wang, Y. Zhang, Y. Liu, B. Tang, Z. Bai and S. Dou, Carbon, 2018, 134, 222-231.

27 X. Hu, J. Chen, G. Zeng, J. Jia, P. Cai, G. Chai and Z. Wen, J. Mater. Chem. A, 2017, 5, 23460-23470.

28 Y. Yang, M. T. McDowell, A. Jackson, J. J. Cha, S. S. Hong and Y. Cui, Nano Lett., 2010, 10, 1486-1491.

29 G. Zhou, H. Tian, Y. Jin, X. Tao, B. Liu, R. Zhang, Z. W. Seh, D. Zhuo, Y. Liu, J. Sun, J. Zhao, C. Zu, D. S. Wu, Q. Zhang and Y. Cui, Proc. Natl. Acad. Sci. U. S. A., 2017, 114, 840-845.

30 L. Wang, Y. Wang and Y. Xia, Energy Environ. Sci., 2015, 8, 1551-1558.

31 D. Guan, J. Li, X. Gao and C. Yuan, $R S C A d v ., 2015,5$, 58514-58521.

32 S. Chen, K. Xing, J. Wen, M. Wen, Q. Wu and Y. Cui, J. Mater. Chem. A, 2018, 6, 7631-7638.

33 S. H. Choi and Y. C. Kang, Nano Res., 2015, 8, 1595-1603.

34 Q. Pan, F. Zheng, X. Ou, C. Yang, X. Xiong and M. Liu, Chem. Eng. J., 2017, 316, 393-400.

35 Z. Xing, G. Tan, Y. Yuan, B. Wang, L. Ma, J. Xie, Z. Li, T. Wu, Y. Ren, R. Shahbazian-Yassar, J. Lu, X. Ji and Z. Chen, Adv. Mater., 2020, 32, e2002403.

36 Y.-Z. Wang, X.-Y. Shan, D.-W. Wang, Z.-H. Sun, H.-M. Cheng and $\mathrm{F}$. Li, Joule, 2018, 2, 1278-1286.

37 X. Li, J. Zai, S. Xiang, Y. Liu, X. He, Z. Xu, K. Wang, Z. Ma and X. Qian, Adv. Energy Mater., 2016, 6, 1601056.

38 H. Lin, L. Yang, X. Jiang, G. Li, T. Zhang, Q. Yao, G. W. Zheng and J. Y. Lee, Energy Environ. Sci., 2017, 10, 1476-1486.

39 Y. Wei, Z. Kong, Y. Pan, Y. Cao, D. Long, J. Wang, W. Qiao and L. Ling, J. Mater. Chem. A, 2018, 6, 5899-5909.

40 P. T. Dirlam, J. Park, A. G. Simmonds, K. Domanik, C. B. Arrington, J. L. Schaefer, V. P. Oleshko, T. S. Kleine,
K. Char, R. S. Glass, C. L. Soles, C. Kim, N. Pinna, Y. E. Sung and J. Pyun, ACS Appl. Mater. Interfaces, 2016, 8, 13437-13448.

41 M. D. Walle, K. Zeng, M. Zhang, Y. Li and Y.-N. Liu, Appl. Surf. Sci., 2019, 473, 540-547.

42 P. Han, S. H. Chung and A. Manthiram, ACS Appl. Mater. Interfaces, 2018, 10, 23122-23130.

43 L. Sygellou, Appl. Surf. Sci., 2019, 476, 1079-1085.

44 X. Li, R. Liu, C. Xu, Y. Bai, X. Zhou, Y. Wang and G. Yuan, Adv. Funct. Mater., 2018, 28, 1800064.

45 T. Zhang, L.-B. Kong, M.-C. Liu, Y.-H. Dai, K. Yan, B. Hu, Y.-C. Luo and L. Kang, Mater. Des., 2016, 112, 88-96.

46 L. Kumari, Y.-R. Ma, C.-C. Tsai, Y.-W. Lin, S. Y. Wu, K.-W. Cheng and Y. Liou, Nanotechnology, 2007, 18, 115717.

47 H. Liu, D. Su, R. Zhou, B. Sun, G. Wang and S. Z. Qiao, Adv. Energy Mater., 2012, 2, 970-975.

48 Z. Deng, H. Jiang, Y. Hu, Y. Liu, L. Zhang, H. Liu and C. Li, Adv. Mater., 2017, 29, 1603020.

49 A. Yanilmaz, A. Tomak, B. Akbali, C. Bacaksiz, E. Ozceri, O. Ari, R. T. Senger, Y. Selamet and H. M. Zareie, RSC Adv., 2017, 7, 28383-28392.

50 Z. R. Ismagilov, A. E. Shalagina, O. Y. Podyacheva, A. V. Ischenko, L. S. Kibis, A. I. Boronin, Y. A. Chesalov, D. I. Kochubey, A. I. Romanenko, O. B. Anikeeva, T. I. Buryakov and E. N. Tkachev, Carbon, 2009, 47, 1922-1929.

51 Y. Qiu, X. Zhang and S. Yang, Phys. Chem. Chem. Phys., 2011, 13, 12554-12558.

52 Y. Zhao, Z. Wang, X. Zhao, X. Wang, K.-H. Lam, F. Chen, L. Zhao, S. Wang and X. Hou, Energy Fuels, 2020, 34, 10188-10195.

53 F. Ma, Y. Wan, X. Wang, X. Wang, J. Liang, Z. Miao, T. Wang, C. Ma, G. Lu, J. Han, Y. Huang and Q. Li, ACS Nano, 2020, 14, 10115-10126.

54 Y. Jiang, M. Wei, J. Feng, Y. Ma and S. Xiong, Energy Environ. Sci., 2016, 9, 1430-1438.

55 X. Zhou, Y. Zhong, M. Yang, M. Hu, J. Wei and Z. Zhou, Chem. Commun., 2014, 50, 12888-12891.

56 Q.-Y. Li, Q.-C. Pan, G.-H. Yang, X.-L. Lin, Z.-X. Yan, H.-Q. Wang and Y.-G. Huang, J. Mater. Chem. A, 2015, 3, 20375-20381.

57 Q. Pan, F. Zheng, Y. Wu, X. Ou, C. Yang, X. Xiong and M. Liu, J. Mater. Chem. A, 2018, 6, 592-598.

58 S. Zhang, G. Wang, Z. Zhang, B. Wang, J. Bai and H. Wang, Small, 2019, 15, 1900565.

59 Y. Fang, Y. Lv, R. Che, H. Wu, X. Zhang, D. Gu, G. Zheng and D. Zhao, J. Am. Chem. Soc., 2013, 135, 1524-1530.

60 X. Huang, K. Qian, J. Yang, J. Zhang, L. Li, C. Yu and D. Zhao, Adv. Mater., 2012, 24, 4419-4423.

61 J. Wang, J. Polleux, J. Lim and B. Dunn, J. Phys. Chem. C, 2007, 111, 14925-14931. 